\title{
Effect of a delayed-action phenytoin preparation on blood phenytoin concentration
}

\author{
F. BOCHNER, W. D. HOOPER, J. H. TYRER, AND M. J. EADIE \\ From the Department of Medicine, University of Queensland, Brisbane, Australia
}

SUMMARY In a cross-over study in a group of epileptic patients it was shown that replacement of the evening dose of an ordinary phenytoin preparation with the same phenytoin dose in a delayed- $\frac{\bar{c}}{\bar{c}}$ action preparation produced no significant change in the next morning's mean blood phenytoin $\frac{\widehat{\otimes}}{\otimes}$ concentration. However, replacement of the entire daily dose of an ordinary phenytoin preparation with the delayed-action preparation did increase mean blood phenytoin levels after some days, possibly because the latter preparation contained an additional $6 \%$ active drug, as compared with. the former. In most circumstances, it seems doubtful if the delayed-action preparation offers any advantage over ordinary phenytoin in treating epilepsy.

Delayed-action preparations of phenytoin (diphenylhydantoin) have been used at times in the treatment of epilepsy. These preparations contain acid phenytoin, whereas ordinary phenytoin preparations usually consist of the sodium salt. The rationale for the use of delayed-action preparations presumably lies in the belief that they may have a more prolonged therapeutic effect than ordinary preparations. For example, if the delayed-action phenytoin is taken in the evening in place of ordinary phenytoin, it might be hoped that it would produce by the next morning higher blood and tissue concentrations of phenytoin than would the ordinary preparation, thus reducing the risk of an early morning epileptic seizure. Certainly there is evidence (Dill, Kazenko, Wolf, and Glazko, 1956) that, after single doses, blood phenytoin levels are maintained for longer periods by acid phenytoin than by sodium phenytoin.

Data have accumulated showing how slowly phenytoin disappears from the blood after its administration is ceased, its half-life being a matter of some $22 \pm 9$ hours (Arnold and Gerber, 1970). Therefore it seems unlikely that omission of phenytoin doses for some 12 hours during the night would produce any profound fall in blood and tissue phenytoin concentrations by the next morning. Since it is known that blood phenytoin concentration correlates with its biological effect (Kutt and McDowell, 1968), the rationale for using a delayed-action preparation of phenytoin at night, or at other times, appea uncertain. We have attempted to see if delayes. action phenytoin offers advantages over the ordinary preparation by investigating the res-O ponse of blood phenytoin concentrations \&o응 replacement of oral doses of ordinary phenyto by similar doses in a delayed-action preparatio $\overrightarrow{0}_{\overrightarrow{0}}$ which is currently available on the Australiann market.

\section{METHODS}

Two studies were carried out. In the first, blood phenytoin concentration was measured by the Wallace (1966) spectrophotometric assay. In theo second, plasma phenytoin concentration was measured by a minor modification of the MacGee (1970) gas chromatographic assay.

The first study was designed to approximate tō the conditions under which the delayed-action phenytoin often is used in practice. Eleven epileptic patients taking phenytoin, and with chronic neuro logical illness necessitating long-term hospitaliza tion, were divided into groups of five and six. AlR entered the trial simultaneously. They continued tof receive all their pre-trial therapy in unchanged dosages throughout the study but group A took theip. evening phenytoin dose $(100 \mathrm{mg})$ as the delayed action preparation for the first 10 days of the study? and then crossed-over to receive their evening dose 682 
as ordinary phenytoin for the second 10 days. Group B took the above phenytoin preparations in the reverse order during the same time periods. Blood was taken for phenytoin estimation between 8 a.m. and 9 a.m. on the mornings after the eighth, ninth, and tenth days of each trial period.

In the second study six patients from the population described above were divided into groups of three. All patients were taking $100 \mathrm{mg}$ phenytoin three times a day and all entered the 14 day trial simultaneously. One group took their entire daily phenytoin dose as the delayed-action preparation (in three doses) for the first week and then reverted to taking the ordinary phenytoin preparation, while all of the second group took the two preparations in reverse order. Blood phenytoin concentrations were measured on the second, fourth, and seventh days of each trial period.

\section{RESULTS}

The results of the first part of the study are set out in Table 1. The delayed-action phenytoin given in a single dose in the evening did not produce higher mean blood phenytoin levels the next morning than the mean levels produced by ordinary phenytoin, an analysis of variance showing that the difference between the means was not significant statistically $(P>0 \cdot 05)$.

The inference could be drawn from the above finding that ordinary phenytoin and the delayedaction phenytoin were equivalent on a dose for dose basis. However the findings for the second

TABLE 1

BLOOD PHENYTOIN CONCENTRATION ON MORNINGS AFTER THE 8TH, 9TH, AND 10TH DAYS OF EACH TRIAL PERIOD*

\begin{tabular}{|c|c|c|c|c|c|c|}
\hline \multirow[t]{2}{*}{ Subject } & \multicolumn{3}{|c|}{$\begin{array}{l}\text { Ordinary phenvtoin } \\
(\mu \mathrm{g} / \mathrm{ml} .)\end{array}$} & \multicolumn{3}{|c|}{$\begin{array}{c}\text { Delayed-action phenytoin } \\
(\mu \mathrm{g} / \mathrm{ml} .)\end{array}$} \\
\hline & Day 8 & Day 9 & Day 10 & Day 8 & Day 9 & Day 10 \\
\hline A & $8 \cdot 4$ & $6 \cdot 2$ & $10 \cdot 6$ & $5 \cdot 5$ & $7 \cdot 4$ & $10 \cdot 6$ \\
\hline B & $3 \cdot 3$ & $3 \cdot 3$ & $4 \cdot 7$ & 0.6 & $2 \cdot 2$ & $1 \cdot 5$ \\
\hline C & $23 \cdot 4$ & $36 \cdot 2$ & $20 \cdot 7$ & $20 \cdot 0$ & $22 \cdot 0$ & $24 \cdot 2$ \\
\hline D & 6.0 & $9 \cdot 6$ & $(7 \cdot 7) \dagger$ & $6 \cdot 3$ & $5 \cdot 5$ & $6 \cdot 8$ \\
\hline $\mathrm{E}$ & $2 \cdot 0$ & 0.9 & $3 \cdot 7$ & $1 \cdot 5$ & $2 \cdot 8$ & $3 \cdot 8$ \\
\hline $\mathrm{F}$ & 36.9 & $33 \cdot 6$ & $36 \cdot 6$ & $45 \cdot 4$ & $32 \cdot 4$ & $33 \cdot 8$ \\
\hline G & $2 \cdot 8$ & $4 \cdot 5$ & $5 \cdot 3$ & $2 \cdot 1$ & 3.0 & $6 \cdot 3$ \\
\hline $\mathrm{H}$ & $18 \cdot 8$ & $19 \cdot 3$ & $20 \cdot 8$ & $18 \cdot 9$ & $17 \cdot 8$ & $19 \cdot 7$ \\
\hline I & $1 \cdot 0$ & 1.9 & $2 \cdot 3$ & 0.9 & 0.6 & $1 \cdot 7$ \\
\hline $\mathbf{J}$ & $9 \cdot 7$ & $9 \cdot 0$ & $11 \cdot 1$ & $14 \cdot 2$ & $13 \cdot 5$ & $14 \cdot 8$ \\
\hline $\mathrm{K}$ & $17 \cdot 5$ & $61 \cdot 4$ & $20 \cdot 9$ & $18 \cdot 0$ & $17 \cdot 1$ & $20 \cdot 9$ \\
\hline Means & & $12 \cdot 73$ & & & $12 \cdot 16$ & \\
\hline
\end{tabular}

* The first five patients took the delayed-action preparation first. $\dagger$ Missing value calculated after Goulden (1952). part of the study did not confirm this (Table 2). There was no statistically significant difference between mean plasma phenytoin levels before the patients entered the trial $(21.9 \mu \mathrm{g} / \mathrm{ml}$.) and after seven days of taking the ordinary phenytoin preparation $(22.8 \mu \mathrm{g} / \mathrm{ml}$.) $(t=0.9, \mathrm{P}>0.40)$, but mean plasma phenytoin level rose significantly

TABLE 2

BLOOD PHENYTOIN LEVELS IN $\mu \mathrm{G} /$ ML. PRODUCED BY THE ORDINARY AND THE DELAYED-ACTION PREPARATIONS

\begin{tabular}{|c|c|c|c|c|c|c|c|}
\hline \multirow{3}{*}{ Subject } & \multirow{3}{*}{ Pre-trial } & \multicolumn{6}{|c|}{ Blood phenytoin concentration } \\
\hline & & \multicolumn{3}{|c|}{ Ordinary preparation } & \multicolumn{3}{|c|}{$\begin{array}{c}\text { Delayed-action } \\
\text { preparation }\end{array}$} \\
\hline & & Day 2 & Day 4 & Dav 7 & Day 2 & Day 4 & Day 7 \\
\hline A & $8 \cdot 4$ & $9 \cdot 5$ & $12 \cdot 7$ & $10 \cdot 7$ & $12 \cdot 8$ & $11 \cdot 3$ & $17 \cdot 6$ \\
\hline B & $22 \cdot 2$ & 26.4 & $25 \cdot 2$ & $20 \cdot 8$ & 23.8 & $30 \cdot 3$ & $27 \cdot 5$ \\
\hline C & 22.9 & 31.9 & $28 \cdot 4$ & $23 \cdot 3$ & $26 \cdot 5$ & $30 \cdot 3$ & $30 \cdot 7$ \\
\hline$D^{*}$ & $12 \cdot 6$ & $14 \cdot 3$ & 14.0 & $16 \cdot 7$ & - & $12 \cdot 6$ & $15 \cdot 1$ \\
\hline $\mathrm{E}^{*}$ & $30 \cdot 2$ & $35 \cdot 3$ & 23.0 & $27 \cdot 8$ & $31 \cdot 6$ & $34 \cdot 6$ & $35 \cdot 0$ \\
\hline$F^{*}$ & 35.0 & $40 \cdot 5$ & $35 \cdot 7$ & $37 \cdot 2$ & $42 \cdot 0$ & $47 \cdot 5$ & $48 \cdot 1$ \\
\hline Mean & 21.9 & $26 \cdot 3$ & $23 \cdot 2$ & $22 \cdot 8$ & $24 \cdot 7$ & $27 \cdot 8$ & 29.0 \\
\hline
\end{tabular}

* Took the delayed-action preparation first.

to $29.0 \mu \mathrm{g} / \mathrm{ml} .(t=3.64, \mathrm{P}<0.02)$ after one week of replacement of the ordinary phenytoin preparation with the delayed-action phenytoin.

\section{DISCUSSION}

At first sight the two studies appear to have produced conflicting findings, but to some extent they can be reconciled. It is clear that no evidence has been obtained that, in a group of patients, the delayed-action phenytoin given, as it often is, in a dose of $100 \mathrm{mg}$ at night, produces higher mean blood phenytoin levels the next morning than does the same dose of ordinary phenytoin. This finding, which might be anticipated from knowledge of phenytoin metabolism in man, suggests that the traditional use of delayed-action phenytoin at night offers no advantage over the use of ordinary phenytoin preparations. Yet, despite this, the delayedaction phenytoin preparation has been shown in the second part of the study to produce higher mean blood phenytoin levels than the ordinary preparation. There are two possible reasons why 
the second part of the study may have shown this effect, whereas the first part did not. The doses of delayed-action phenytoin used in the second part were three times as high as those used in the first part, and the second part of the study happened to be carried out in a group of patients who had a substantially higher mean blood phenytoin level (around $21.9 \mu \mathrm{g} / \mathrm{ml}$.) than that in the first part $(12.7 \mu \mathrm{g} / \mathrm{ml}$.). It has been shown (Bochner, Hooper, Tyrer, and Eadie, 1972) that, at higher blood phenytoin levels, small dosage changes have proportionately greater effects on blood phenytoin concentration than they do at lower blood levels. Therefore the second study was, as it were, set to be a more sensitive detector of differences than was the first study. Its findings suggest that the delayed-action phenytoin, dose for dose, may have contained slightly more active ingredient than the ordinary preparation.

In the delayed-action preparation the phenytoin is present as the free acid (molecular weight $252 \cdot 3$ ), whereas in the ordinary preparation the drug is present as the sodium salt (molecular weight $268 \cdot 3$ ). If both preparations contain $100 \mathrm{mg}$ of active ingredient-that is, acid phenytoin, or sodium phenytoin-the delayed action preparation should contain some $6.34 \%$ more phenytoin itself than the ordinary preparation, and this has been confirmed by assay. This difference in phenytoin contents may be too small to have a significant effect in the majority of patients when only $100 \mathrm{mg}$ of the delayedaction phenytoin preparation is taken each night, but in the occasional patient whose blood phenytoin concentration already is fairly high in the so-called 'therapeutic' range of 10-20 $\mu \mathrm{g} / \mathrm{ml}$., the delayed-action phenytoin may produce an increment in blood phenytoin concentration which would be of therapeutic value. This could explain some clinicians' impressions that the delayed-action preparation sometimes has been of use. While it could be argued that slightly higher oral dose of an ordinary phenyo toin preparation would have been equalls helpful, in practice it may be difficult to provide this slightly higher dose because oral phenytoif preparations usually are available only in $30 \mathrm{mg}_{\text {Q }}^{\top}$ $50 \mathrm{mg}$, and $100 \mathrm{mg}$ units and in the circumstances where delayed-action phenytoin might produce useful rise in blood phenytoin level-namely, when the level is in the range $15-20 \mu \mathrm{g} / \mathrm{ml} . \overrightarrow{\vec{c}}$ even a further $30 \mathrm{mg}$ phenytoin daily may lead़ to a marked rise in blood phenytoin level wits drug intoxication (Bochner et al., 1972).

It appears that the slightly greater content o phenytoin in the delayed-action preparation tested, rather than any difference in its duration of action, may provide a sufficient explanation for the occasional therapeutic advantage this preparation may have.

The authors desire to thank Dr. B. Lucas, of ParkE Davis and Co., for his interest in the studies, and for making available phenytoin preparations for testiđigg?

\section{REFERENCES}

Arnold, K., and Gerber, N. (1970). The rate of decling diphenylhydantoin in human plasma. Clinical Pharmacesto gy and Therapeutics, 11, 121-134.

Bochner, F., Hooper, W. D., Tyrer, J. H., and Eadie, M尺ि (1972). The effect of dosage increments on blood pheny审i concentration. Journal of Neurology, Neurosurgery, 플 Psychiatry, in press.

Dill, W. A., Kazenko, A., Wolf, L. M., and Glazko, A. (1956). Studies on 5,5'-diphenylhydantoin (Dilantin) in animals and man. Journal of Pharmacology and Experiment Therapeutics, 118, 270-279.

Goulden, C. H. (1952). Methods of Statistical Analysis. 2n edn. Wiley: New York.

Kutt, H., and McDowell, F. (1968). Management of epileps焉 with diphenylhydantoin sodium. Dosage regulation fo\$ problem patients. Journal of the American Medical Asso ciation, 203, 969-972.

MacGee, J. (1970). Rapid determination of diphenylhydan toin in blood plasma by gas-liquid chromatography Analytical Chemistry, 42, 421-422.

Wallace, J. E. (1966). Spectrophotometric determination of diphenylhydantoin. Journal of Forensic Science, 11, 552559. 